\title{
Development of Transport for Disabled People on the Example of Wheelchair Propulsion with Cam-Thread Drive
}

\author{
Jarosław Gabryelski ${ }^{1}$, Przemysław Kurczewski ${ }^{1}$, Maciej Sydor ${ }^{2, * \mathbb{D}}$, Agnieszka Szperling ${ }^{1}$, Dariusz Torzyński ${ }^{1}$ \\ and Marek Zabłocki ${ }^{1}$ \\ 1 Faculty of Civil and Transport Engineering, Poznan University of Technology, 60-965 Poznań, Poland; \\ jaroslaw.gabryelski@put.poznan.pl (J.G.); przemyslaw.kurczewski@put.poznan.pl (P.K.); \\ agnieszka.szperling@gmail.com (A.S.); dariusz.torzynski@put.poznan.pl (D.T.); \\ marek.zablocki@put.poznan.pl (M.Z.) \\ 2 Faculty of Forestry and Wood Technology, Poznań University of Life Sciences, 60-637 Poznań, Poland \\ * Correspondence: maciej.sydor@up.poznan.pl
}

Citation: Gabryelski, J.; Kurczewski, P.; Sydor, M.; Szperling, A.; Torzyński, D.; Zabłocki, M. Development of Transport for Disabled People on the Example of Wheelchair Propulsion with Cam-Thread Drive. Energies 2021, 14, 8137. https://doi.org/ $10.3390 /$ en14238137

Academic Editor: Ewa Glińska

Received: 19 October 2021

Accepted: 2 December 2021

Published: 4 December 2021

Publisher's Note: MDPI stays neutral with regard to jurisdictional claims in published maps and institutional affiliations.

Copyright: (C) 2021 by the authors. Licensee MDPI, Basel, Switzerland. This article is an open access article distributed under the terms and conditions of the Creative Commons Attribution (CC BY) license (https:/ / creativecommons.org/licenses/by/ $4.0 /)$.

\begin{abstract}
The increasingly frequent use of electric drives is a new direction of development in personal transport. Sometimes these drives take over the work of human muscles, and sometimes they only support them. This is particularly evident in means of transport such as bicycles and scooters, but also in transporting people with disabilities. This study questions whether this is the only right development direction, and explores the possibility of developing means of transport for the more effective use of human muscles by proposing new structural solutions. We identified that such an action favors the minimization of the environmental load generated by technical facilities and, at the same time, may be a response to social needs resulting from the principles of sustainable development. This paper presents the operation principle of the innovative Wheelchair Cam-thread Drive (WCD), followed by field tests, laboratory measurements and biomechanical analyses of the WCD, comparing it with a typical Wheelchair Push-rim Drive (WPD). We found that the WCD allows efficient driving on flat and level surfaces, but its propulsion method can adversely alter the location of the center of gravity on the human-wheelchair system. A brake is also required to control the driving speed. Ultimately, the WCD was found to put less strain on the human movement system, so it could be used for rehabilitation exercises. The WCD appears to be a promising design, deserving further research into the drive biomechanics and the optimization of the mechanism operation. Such an innovative manual drive presents an interesting alternative to electric drives.
\end{abstract}

Keywords: alternative sustainable transport; muscle energy; muscle drive; wheelchair; wheelchair propulsion; self-propelled wheelchair; person with a disability; sustainable personal transport; personal transporter; eco-friendly drive

\section{Introduction}

The electric drives in personal transport appears an important direction for their development. Wherever significant driving power is needed, such solutions are becoming increasingly popular and are being taken into account when designing various means of transport. Obvious consequences include increasing adverse environmental, social, and economic burdens. Although this burden is lower when electric drives replace combustionbased solutions, it is still higher than in the case of propulsion systems based on human biological forces.

In restricting the area of application for propulsion systems for individual means of transport to journeys with relatively short distances, improvements in the efficiency of these propulsion systems, based on broadly understood human biological forces, might gain importance. Consequently, many advantages follow; as we know, walking or cycling provide significant health benefits. Furthermore, cycling represents an effective form of transport for distances of up to $5 \mathrm{~km}$, making it particularly suitable for inner-city 
journeys [1]. The positive effects of exercise on the human body are even more pronounced for wheelchair users. Despite the current widespread use of electric drives in wheelchairs, and their easy application in these means of transport, they do not yet dominate the wheelchair sales market. However, the health advantages of manual propulsion are discussed in numerous publications. Manual wheelchair drives require the use of the upper limb and shoulder girdle muscles. Frequent and significant use of muscular forces in transport can cause various body injuries in the form of, for example, the overloading of the muscular system, and arthritis. Therefore, solutions have been sought that would reduce these adverse effects, without depriving the users of mobility.

For example, in the case of a wheelchair with partial electrical support [2], a reduced load was found on the arm and the cardiovascular system during propulsion, compared with a manual drive. Precision movement tasks have also been reported to be easier to perform in a typical manual wheelchair. Electrically supported drives can be beneficial for users for whom a typical manual wheelchair drive can cause arm injuries, and for those who have insufficient arm strength or cardiorespiratory reserve. In the absence of such exemplary contraindications, we can conclude that the development of manual wheelchair drives can provide several benefits, and be part of the rehabilitation process.

The use of power scooters and wheelchairs have also been found to contribute to an increased risk of obesity [3]. The lack of exercise in power wheelchair users should therefore be compensated by increased physical activity [4]. Coupled with a degenerated musculoskeletal system, obesity can increase the risk of heart disease and diabetes. Among other things, physical activity increases cardiovascular fitness and allows participation in recreational and competitive sports.

A wheelchair for daily use is an individually chosen vehicle [5-9] with two main functions; it stabilizes the body in space and promotes mobility [10]. Manual self-propelled wheelchairs can be classified as sports wheelchairs and everyday wheelchairs [11]. The function and propulsion efficiency of a wheelchair directly affect its user's social participation [12-14]; however, its use involves a risk of injury related to wheelchair propulsion [15] and potential falls [16,17]. Various drive options are used to increase the drive capability of a wheelchair. Different drive methods can be used, including: directly with two push-rims [18]; directly with one hand push-rim [19]; with push-rims and power-assisted devices [11]; push-rims and a gearbox [20]; crank drive [21], and lever drive [22]. Other, less typical propulsion methods are also used, for example with a walking mechanism [23] or a pulley drive mechanism $[24,25]$. Wheelchairs driven differently than directly by the rims (e.g., with a crank and lever drive) are usually more efficient and less burdensome for the human movement system, but at the same time less maneuverable indoors [18]. Unlike other drives, the Wheelchair Cam-thread Drive (WCD), allows the propulsive motion to be performed alternatively in multiple directions, in the sagittal and frontal plane of the human body, which is a great advantage. Therefore, we found this drive to be promising, and worth researching. The propulsion mechanism under investigation is the result of our work, and a patent application was filed for this invention [26].

\section{Materials and Methods}

\subsection{Materials}

The innovative Wheelchair Cam-thread Drive (WCD) is presented in Figure 1.

A wheel with WCD can be fitted to any self-propelled manual wheelchair, using standard quick-release axles. A cam disk (Figure 1e), on which the drive wrapping cable is wrapped, allows the obtainment of variable power transmission in a single drive cycle. Figure 2 presents two different cam disks: spiral and a biomechanical. The biomechanical cam was created based on strength data of the human upper limb from the Human Measurement Atlas [27]. When creating the biomechanical cam, we took into account the fact that during the driving movement from position 1 to position 4 , the strength capacity of the human upper limbs decreases; therefore, the cam radii were reduced proportionally (radius from $r_{1}$ to $r_{4}$ ). The initial radius $r_{1}$ of the cam is slightly larger than the radius of the push-rim in a typical wheelchair. A 
spline smoothing curve was applied between points $1^{\prime}$ to $4^{\prime}$ on the cam. The intervals from $d_{1^{\prime}}$ to $d_{4^{\prime}}$ measured along the cam arc between points 1 to 4 are identical in length to the rectilinear intervals $d_{1}$ to $d_{4}$ when the propelling cable is pulled.
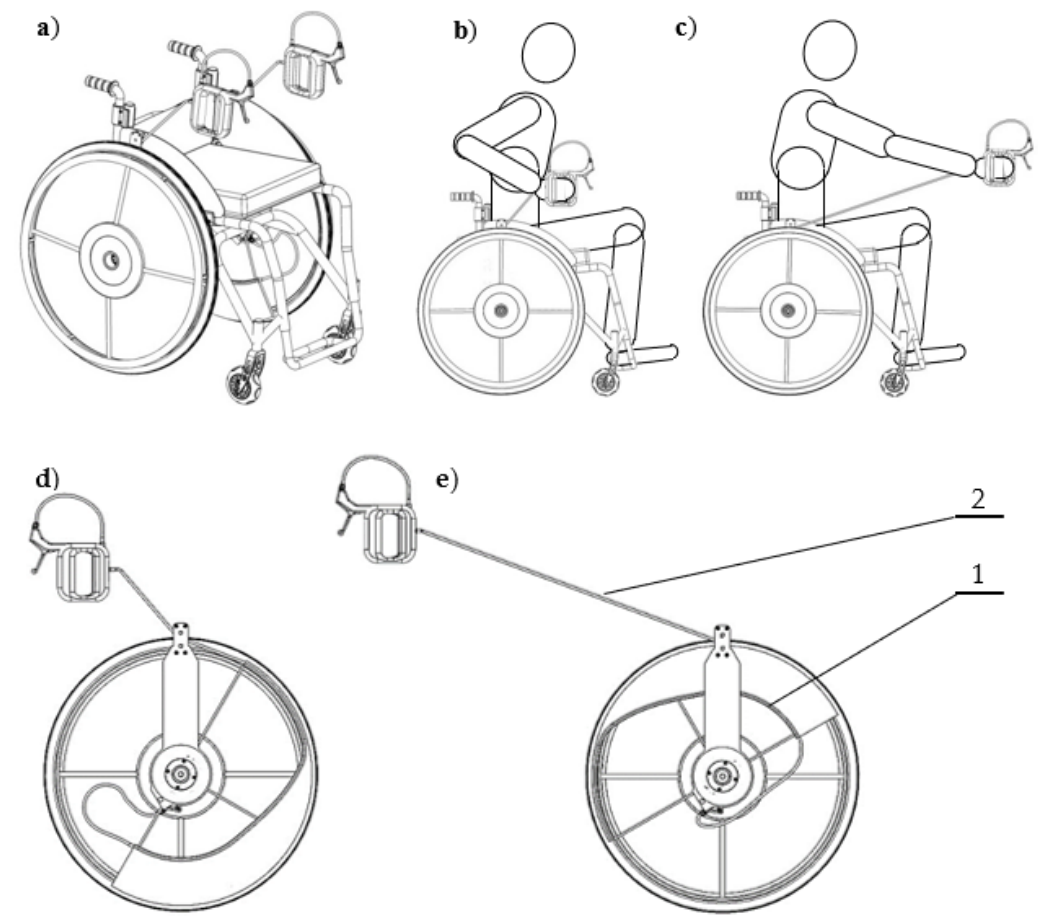

Figure 1. Wheelchair Cam-thread Drive (WCD): (a) - general view of a wheelchair with WCD; (b) —initial drive phase; (c) — final drive phase; (d) —a wheel in the drive-ready phase; (e)—a wheel with a propelling cable pulled out (1-the cable; 2 -the routing tube).
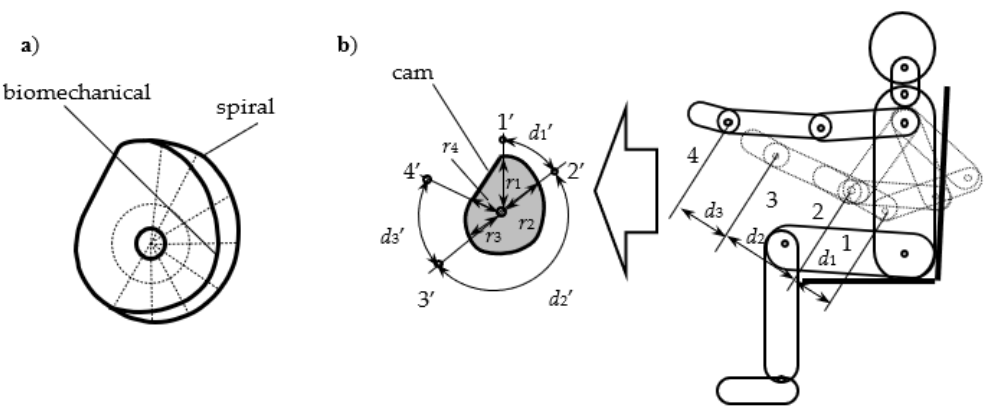

Figure 2. Cams: (a)—spiral and biomechanical; (b) — the idea of a biomechanical cam (designations: $1,2,3,4$-successive limb positions when pulling the propelling cable; $1^{\prime}, 2^{\prime}, 3^{\prime}, 4^{\prime}$ - successive points for building the cam geometry; $d_{1}, d_{2}, d_{3}$-distances obtained when pulling the propelling cable; $d_{1^{\prime}}$, $d_{2^{\prime}}, d_{3^{\prime}}$-distances corresponding to $d_{1}, d_{2}, d_{3}$ measured along the curve; $r_{2}, r_{3}, r_{4}$-cam radii).

A cam based on the Archimedean spiral was chosen for the research, because of the more regular character of radius changes and the easier interpretation of the results obtained. The radius $r_{1}$ of the initial section of the cam used for starting is $2 \%$ larger than the radius of the push-rim of a typical wheelchair, whereas the final section $r_{3}$ of the cam has a radius 1.5 times smaller than the initial radius, and is close to the diameter of the push-rim of a typical marathon wheelchair (which allows faster driving). Thanks to a cam, it is possible to propel the wheelchair using short movements (low load on the human movement system, high drive torque, low travel speed-parameters for uphill travel), or long movements (higher load on the human movement system, low drive torque, high travelling speed-parameters for travelling a flat stretch). 
WCD allows typical drive push-rims to be left; consequently, the wheelchair can be propelled in two different ways, as chosen by the user.

\subsection{Methods}

The study involved three stages: field tests on both compared drives, stationary bench tests, and computer simulations. For safety reasons, the field test was carried out by two able-bodied people: (1) a rehabilitation specialist and (2), a specialist in designing technical aids for people with disabilities (Figure 3).

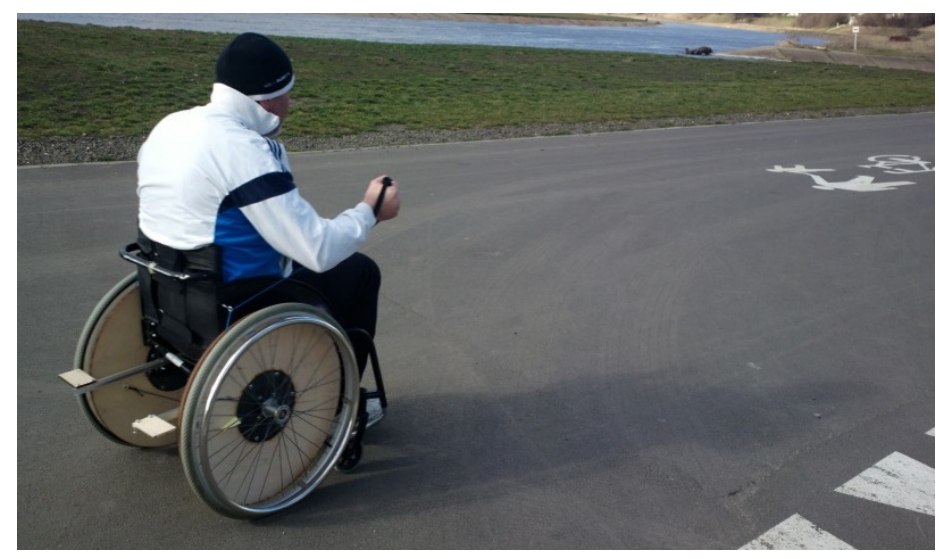

Figure 3. Wheelchair Cam-thread Drive (WCD)—field test.

Driving parameters (distance, speed) and human physical load parameters (heart rate and energy expenditure) were monitored during the field test.

In the second stage, measurements were carried out on the test bench (Figure 4), consisting of the load-bearing frame (1) which carries resistance rollers driven by the drive wheels of the tested wheelchair (2), the mechanism for anchoring the tested wheelchair (3), the ramp (4), and the WCD (5).

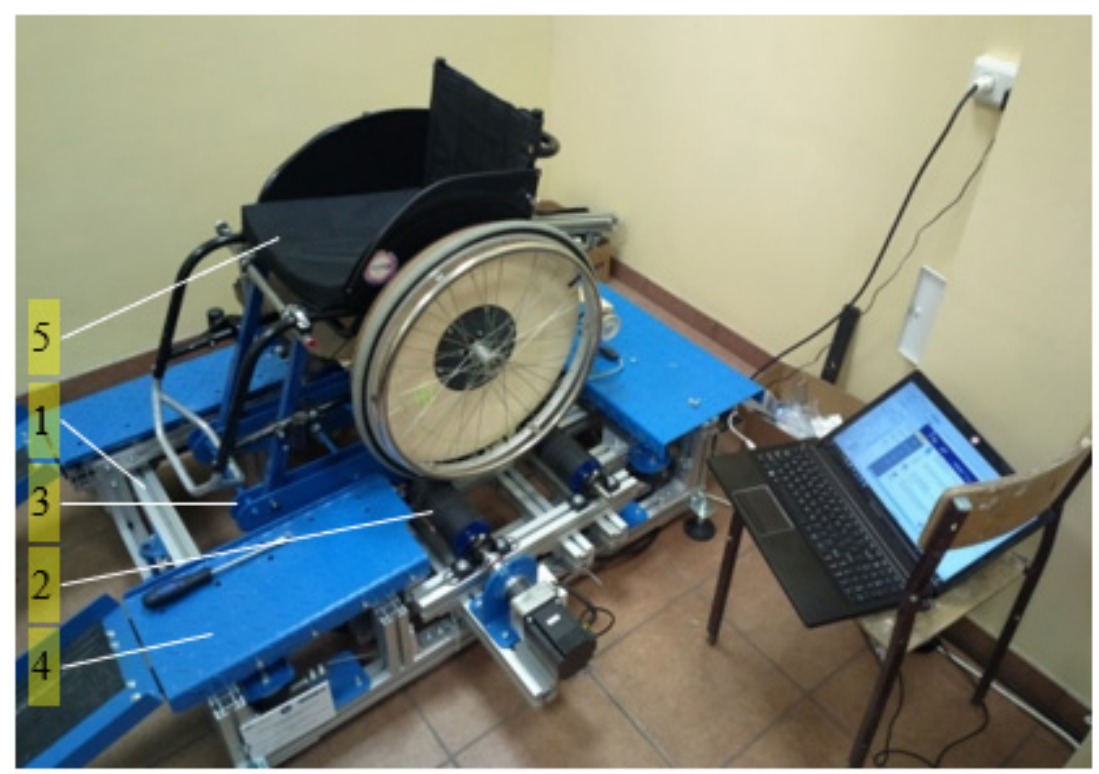

Figure 4. Bench with the prototype wheelchair: 1-bench frame; 2-resistance rollers; 3-anchorage mechanism for the tested wheelchair; 4-ramp, and 5-tested wheelchair.

The sequence of the three propelling movements during the tests is shown in Figure 5. During the tests, signals of bioelectrical activity from the muscles were recorded. An EMG sensor with MyoMuscle software (DTS EMG Sensor model 548 and Mini DTS Receiver 
model 585, Noraxon, Scottsdale, AZ, USA) was used for recording. The right upper limb of an able-bodied woman, $173 \mathrm{~cm}$ tall and with a BMI of $20.4 \mathrm{~kg} / \mathrm{m}^{2}$, was studied (the subject with the lowest available attenuation of the EMG signal was selected for the bench test). Four muscles of the upper limb, which are the most involved in the use of a wheelchair, were selected for EMG measurements: the anterior and posterior part of the shoulder muscle, triceps and the long radial extensor of the wrist. The measuring electrodes were placed in the middle part of these muscles.
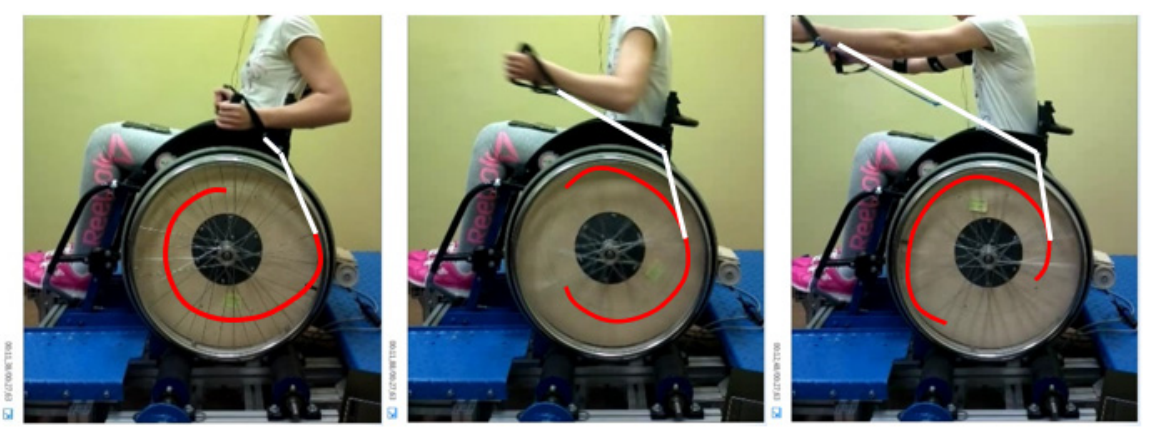

Figure 5. Three stages of drive movement during test-bed EMG tests of a wheelchair prototype with Wheelchair Cam-thread Drive (WCD) (in the figure, the cam shape has been marked with a red line, and the course of the drive cable has been marked with a white line).

The third stage involved computer biomechanical analyses, using the AnyBody Modelling System (AnyBody Technology, Aalborg, Denmark). A model of a seated person containing the upper body, including the pelvis, was used for the analyses. The model characteristics were as follows: $C_{50}$, a male of European origin, aged $20-40$ years. The model used has a complete skeletal system of the trunk, upper limbs and shoulder girdle, covering 290 individual muscles of the shoulder girdle and upper limbs. The employed wheelchair model covered the body support system and drive wheels in the WCD and WPD variant. The analyses aimed to compare the effects of both types of drive on forces in the muscles.

\section{Results}

\subsection{Field Tests}

Table 1 shows the results of the comparative tests for both drives.

Table 1. Results of field tests.

\begin{tabular}{cccccccccc}
\hline Type of Surface & \multicolumn{4}{c}{ Monitored Parameters } & \multicolumn{3}{c}{ Tarmac } & \multicolumn{3}{c}{ Floor Tiles } \\
\hline Person/Drive Type & 1/WCD & 1/WPD & 1/WCD & 1/WCD & 1/WPD & 2/WCD & 2/WPD & 1/WCD & 2/WPD \\
\hline Test duration (min) & 1.27 & 0.57 & 1.24 & 2.24 & 2.03 & 2.49 & 2.2 & 2.27 & 2.42 \\
Distance (m) & 100 & 80 & 100 & 160 & 180 & 160 & 170 & 140 & 120 \\
Max. speed (km/h) & 5.7 & 5.8 & 6.1 & 4.5 & 6.1 & 4.7 & 5.6 & 3.9 & 5.1 \\
Mean speed (km/h) & 4.5 & 4.4 & 4.4 & 4.1 & 5.4 & 3.4 & 4.5 & 3.5 & 5.1 \\
Min. heart rate (bpm) & 85 & 88 & 70 & 96 & 83 & 75 & 93 & 76 & 97 \\
Mean heart rate (bpm) & 94 & 88 & 87 & 107 & 92 & 91 & 100 & 99 & 108 \\
Max. heart rate (bpm) & 106 & 88 & 94 & 120 & 96 & 99 & 121 & 117 & 115 \\
Used energy (kcal) & 7 & 6 & 6 & 17 & 11 & 15 & 14 & 14 & 19 \\
Energy from fat (\%) & 73 & 78 & 78 & 62 & 62 & 65 & 57 & 63 & 54 \\
Height above sea level (m) & 46 & 48 & 48 & 48 & 48 & 48 & 48 & 48 & 48 \\
\hline
\end{tabular}

Symbols: 1—first tested person; 2—second tested person; WCD—Wheelchair Cam-thread Drive; WPD—Wheelchair Push-rim Drive. 
A comparison of the performance parameters of the persons testing wheelchairs with WCD and WPD is presented in Table 1. The test subjects' observations showed that:

- Energy expenditure was greater when driving with the WCD on a tarmac surface, but the driving resistance decreased on a smooth and flat stoneware (stone) surfaces;

- The long cable wrapping distance in the WCD had a positive effect on the use of a longer wheel distance in a single propelling movement, compared with the WPD (at the beginning of the movement, a larger gear ratio allows a smoother start with less load; at the end of the movement, when the cables are pulled out, the ratio is smaller, which enables the achievement of a higher driving speed while maintaining driving comfort);

- Cams in the WCD changed the transmission ratio by approximately $1.5 \times$ and reduced the forces applied in the cables for propulsion; further measures should take into account the change in gear and wheel diameters, and ratios of the cam drive;

- The WCD caused an unfavorable shift towards the center of gravity of the manwheelchair system with the cables extended and the upper limbs in a horizontal position, which made it difficult to travel faster and over uneven ground.

\subsection{Stationary Test-Bed Tests}

The characteristics of the EMG when driving a wheelchair with WCD and WPD are shown in Figures 6 and 7, respectively. Both graphs show the results obtained for the same person.

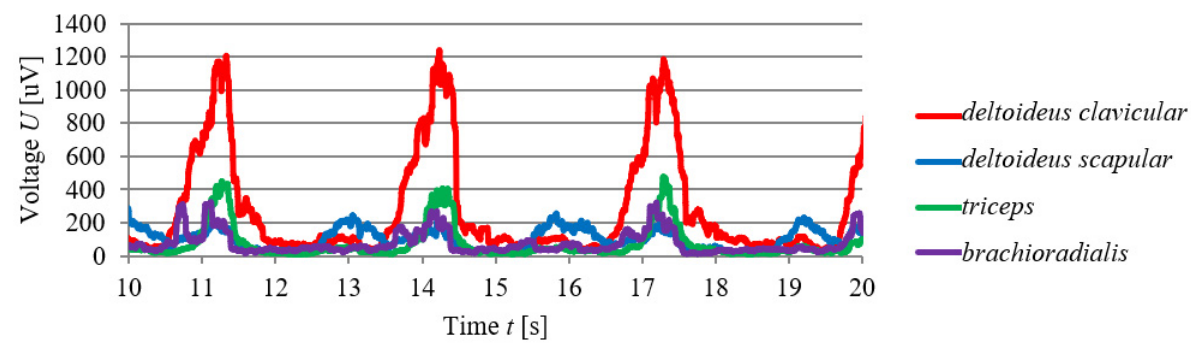

Figure 6. EMG charts for the muscles of the right upper limb for the Wheelchair Cam-thread Drive (WCD).

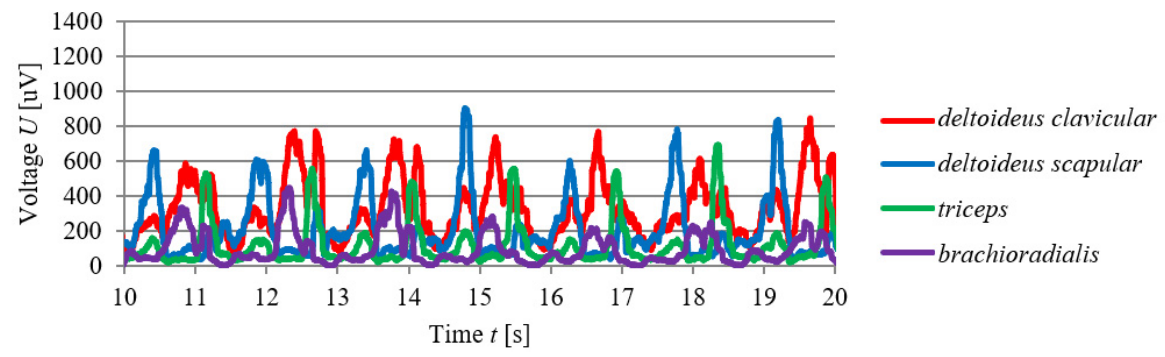

Figure 7. EMG chart for the right upper limb muscles for the Wheelchair Push-rim Drive (WPD).

Figure 8 presents the monitored human muscles.

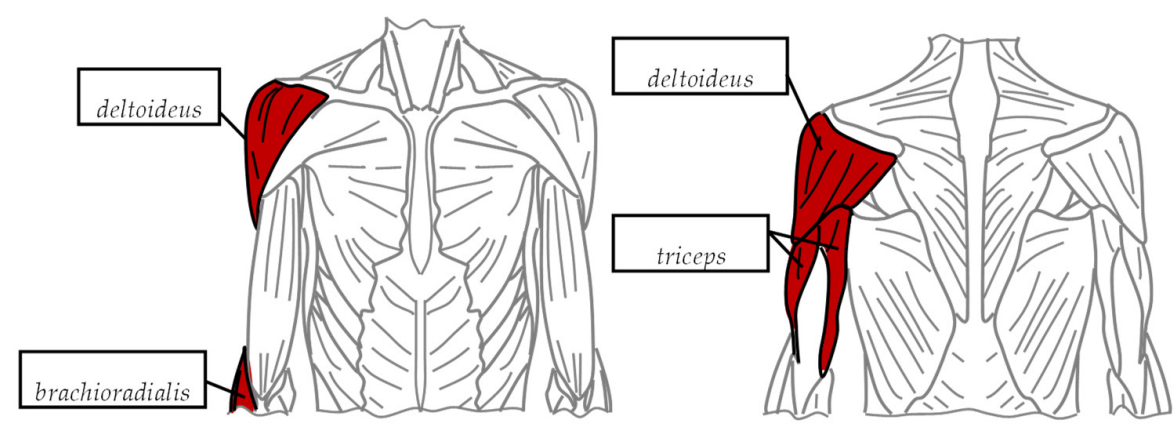

Figure 8. Analyzed muscles. 
The following conclusions can be drawn from the comparative bench studies, which involved monitoring the EMG activity of four muscles during the propulsion of a WCD wheelchair and a WPD wheelchair:

- There is a clear difference in the nature of wheelchair propulsion between WCD and WPD. These are expressed by the differences in the length of the stretch over which the propulsion occurs, the recorded values of the muscle electrical voltage $U$ and the different activities observed over time for the individual muscles;

- High electrical voltage $U$ values were recorded in the anterior part of the anterior deltoideus muscle during wheelchair propulsion with WCD; these values were significantly lower in the other muscles. In WPD, significant muscle voltage values were generated in both the entire deltoideus and triceps muscles. In WPD, the deltoideus scapular muscle generated $U$ voltages similar to those of the deltoideus clavicular muscle. High voltage values in the deltoideus scapular muscle are not typical of WPD and are most likely due to the propulsion technique of the able-bodied tester. The brachioradialis muscle exhibited significantly less activity in total for both WCD and WPD;

- The successive propulsion phases of the wheelchair with WCD were performed less frequently (3.0-3.5 s) than in the wheelchair with WPD (2.0 s), and covered a larger circular distance (longer distance travelled): approximately $\frac{1}{2}$ of the circumference of the wheel for WCD and $\frac{1}{4}$ of the circumference for WPD;

- The maximum values of muscle voltages for the wheelchair with WCD were higher by about 30\% than for the wheelchair with WPD, but about 50\% lower in the triceps,

- The four analyzed muscles activated simultaneously, and their activity significantly faded away in the return movement; this fade-away period in muscle activity was shorter in the WPD wheelchairs.

\subsection{Analysis Using the AnyBody Modelling System}

The active part of the propulsion cycle was subjected to analysis. The propulsion phase was analyzed without the return phase. From the AnyBody analysis, it follows that the muscle activity was acceptable for both drives, and the so-called index of maximum muscle activity (MMA) and muscle forces $F$ were not exceeded. Figures 9 and 10 show a simulation of the human-body movement when propelling the wheelchair. The muscles visible in Figures 9 and 10 (color and cross-section) testify to the magnitude of the generated forces $F$. The larger the muscle cross-section or the darker its color, the greater the muscle forces generated.
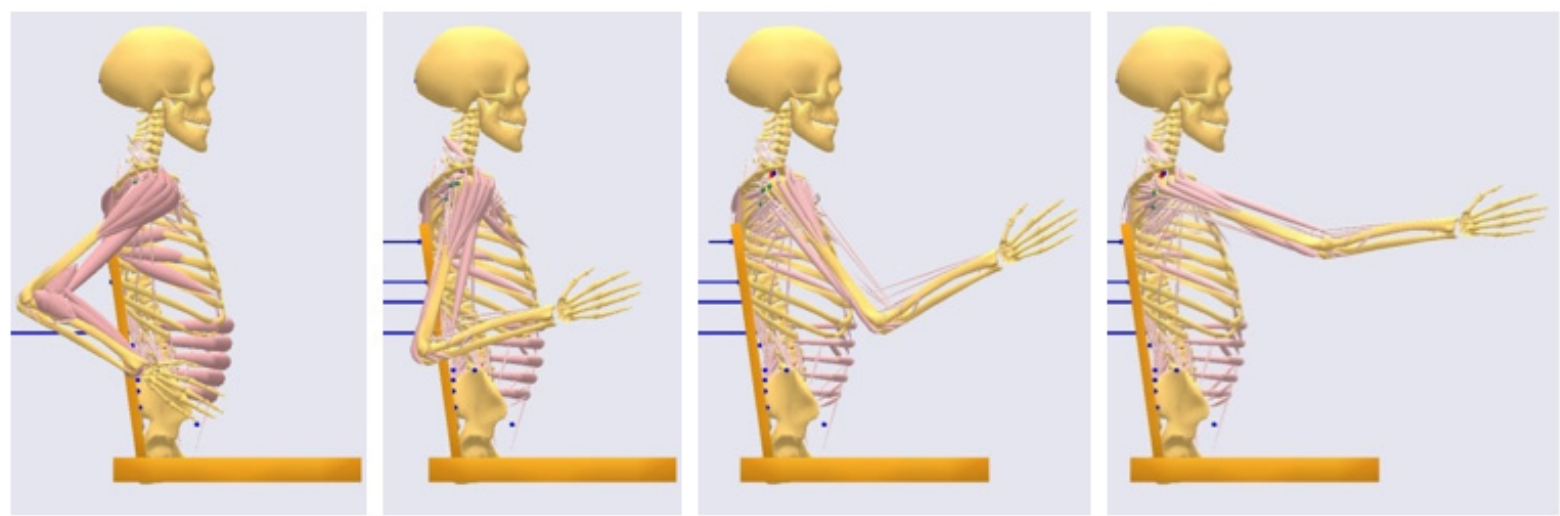

Figure 9. Simulation of movement and human muscle forces when propelling a wheelchair with the Wheelchair Cam-thread Drive (WCD).

The results of the muscle force measurement over time $(F(t))$ obtained from the AnyBody system for both drive types are shown in Figure 11. 


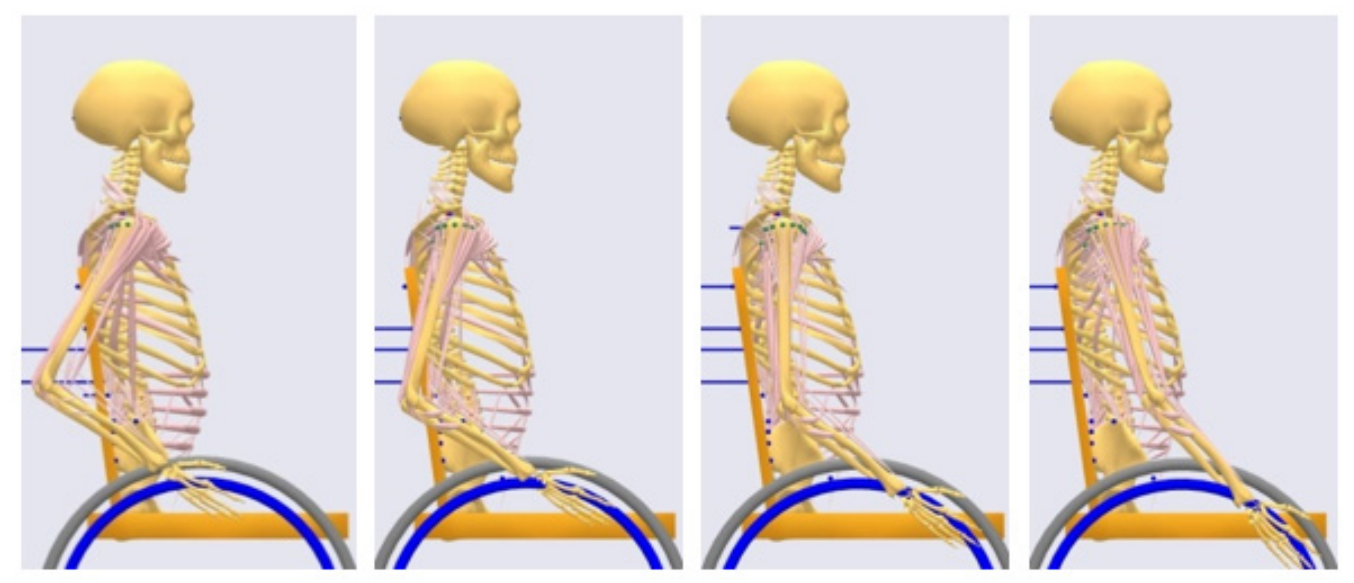

Figure 10. Simulation of movement and human muscle forces when propelling a wheelchair with the Wheelchair Push-rim Drive (WPD).
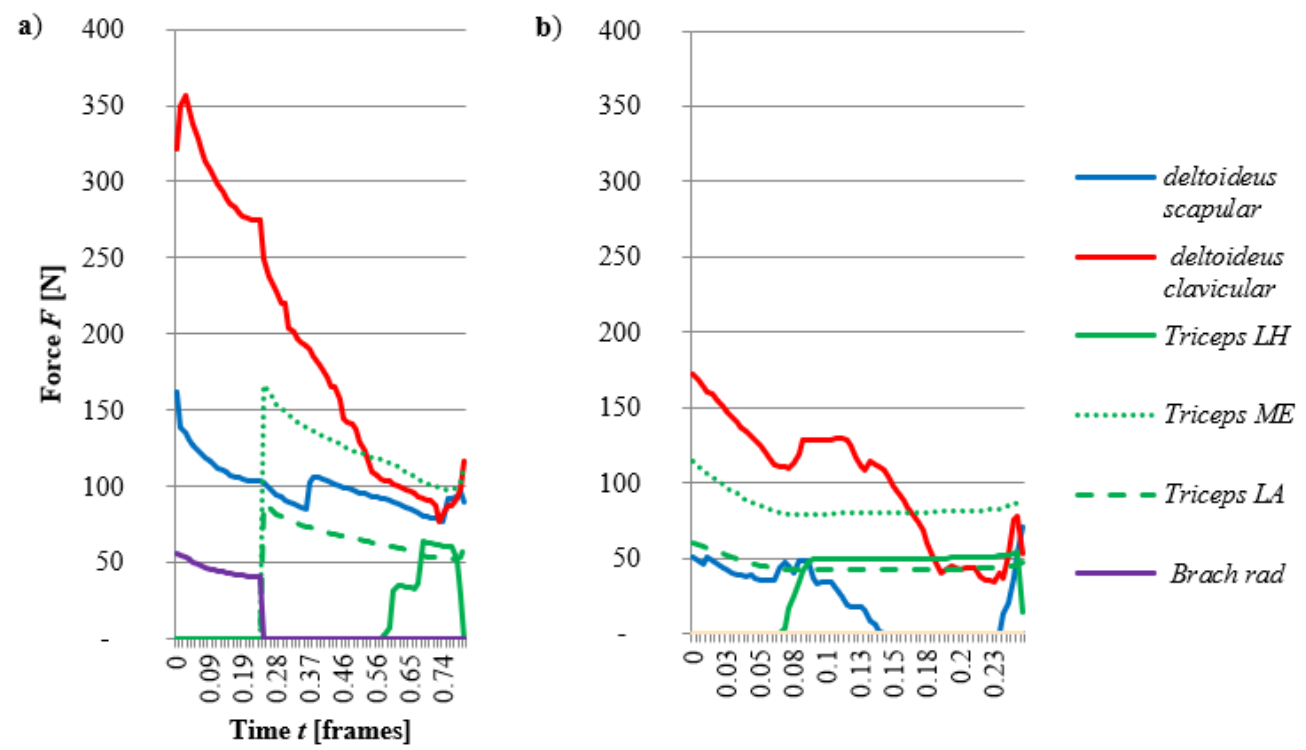

Figure 11. Forces in the upper limb muscles during one propulsion cycle (without the return phase): (a) - the wheelchair with the Wheelchair Cam-thread Drive (WCD); (b) - the wheelchair with the Wheelchair Push-rim Drive (WPD).

The analyses showed that:

- The deltoideus scapular muscle received the most load, for both WCD and WPD. This was evidenced by both the previous EMG studies (Figures 6 and 7) and the analysis of this study (Figure 11). Especially in the WCD movement, the muscle force $F$ decreases (from about $350 \mathrm{~N}$ to about $100 \mathrm{~N}$ ) as the arm straightens. The obtained final value was more than three times lower than the initial one for the WCD and about two times lower for the WPD $(F \approx 50 \mathrm{~N})$. At the same time, the final muscle force value was comparable for both types of drives.

- For the deltoideus scapular muscle, the initial forces for WCD $(F<150 \mathrm{~N})$ were also approximately three times greater than the forces used to propel the WPD. The forces in the muscle decreased as the movement continued, to a value of approximately $F \approx 100 \mathrm{~N}$.

- The forces $F$ in the triceps (LH, ME and LA) at the beginning of the propelling movement were about two times greater for WCD than for WPD and they evened out at the end of the movement. For WPD, at the beginning of the movement, the sum of the $\mathrm{LH}, \mathrm{ME}$ and LA values in the triceps created forces greater in the deltoideus clavicular muscle. With WCD, the force in the muscle only appeared after about ${ }^{1} / 3$ of the entire propulsive movement. 
- For the brachioradialis muscle, clear activity was only visible for WCD, although the previously described EMG studies indicated that activity in this muscle was evident in both drives.

\section{Discussion}

Both of the mechanisms in question, the Wheelchair Cam-thread Drive (WCD) and the Wheelchair Push-rim Drive (WPD), studied the transfer muscle energy to wheelchair movement in a discontinuous manner. The WPD propulsion cycle consisted of an active drive phase and a passive return phase, allowing for some muscle rest. The shoulder flexors and elbow extensors were the main muscles used in the propulsion phase, and the shoulder extensors were the main muscles active in the return phase [28]. In addition, a self-propelled manual wheelchair moved with changing velocity, which had an impact on the temporary location of the center of gravity of the human-wheelchair system. The changeable nature of this influence depended not only on the driving technique, but on the propulsion mechanisms, road characteristics, and the purpose of the movement (driving: fast-slow, left-right, uphill-downhill-flat) $[29,30]$. The cycle frequency, the strength of the propulsive movement (the rim push) and the length of the propulsive movement, can be modified during the wheelchair ride. Physically stronger users were observed to realize propulsion by generating fewer, shorter propulsive rim pushes, at the same time achieving a higher travel speed. Less physically fit users lowered the seat, to allow the generation of longer wheelchair rim drive movements [31,32]. In nonsporting applications, users usually aimed to generate the most mechanically efficient movements possible, avoiding high load on joints and high energy expenditure when moving [33]. The improved driving technique involved, on the one hand, strengthening the shoulder flexors and making better use of the drive phase and, on the other hand, achieving optimal muscle rest during the return phase [28]. A better adaptation of the wheelchair to its user would also result in an improved driving technique $[5-7,34,35]$. This could also consist of a change of the type of wheelchair drive $[9,27,35]$, e.g., to the WCD proposed in this paper.

Wheelchairs with WCD were also analyzed in the literature [28,36]. It was established that the propulsion movement, consisting of bending joints, was more beneficial than the propulsion movement consisting of straightening the joints [24]. An increased shoulder flexor muscle strength was required for using the WCD. The literature suggested $[37,38]$ that strengthening the shoulder flexor muscle was a desirable component of the rehabilitation process, that allows an improvement in the efficiency and technique of the propulsion of wheelchairs. The most likely reason for the appearance of greater movement resistance when using the WCD compared with the WPD was the straightening of the upper limbs in their horizontal position. That is, the end of the propelling movement, combined with the shifting of the center of gravity of the "wheelchair-human" system towards the front casters caused an overload, thus resulting in increased movement resistance. The literature identifies the interdependence between driving efficiency and the shift of the center of gravity of the 'human-wheelchair' system in a typical, manual self-propelled wheelchair, for example, an active wheelchair [29]. Another unfavorable phenomenon observed in the WCD was the rapid fatigue of the upper limbs, forced to stay in a fixed upright and forward-facing position.

There are several possibilities for changing the settings of a wheelchair with WCD, for example, setting the point under the shoulder from which the cable is pulled out, the length of the cables, their spacing over the shoulder width, etc. Comparative field tests, test bench and computer modelling have given some indications for a further search on a solution to reduce the loads on the human body during propulsion. Safety is an important aspect in developing new drives, i.e., how to design a drive that minimizes its harmful effects on the user. So far, a cam with an Archimedean spiral has been tested in a prototype WCD wheelchair (Figure 1). The biomechanical cam should also be researched (Figure 2b), as its geometry is promising. In the WCD, the dynamic forces occurring at the initial and final stages of propulsion need to be mitigated, as such forces can cause dangerous 
overloading of the user's upper limb joints. This phenomenon can be eliminated using elastomer return springs (tubing rubbers) and the use of an elastomer buffer attached to the drive mechanism. No method for WCD propulsion has been developed in which the return phase of the upper limb could have a beneficial effect on reducing fatigue during propulsion (by analogy with wheelchairs with WPD).

About $1 \%$ of people worldwide use wheelchairs [39]. Regardless of the technical aspects of wheelchair design [40] and the rehabilitation benefits for wheelchair users, the question we ask is whether it is reasonable to introduce changes in the design of personal transport means. One way to improve the driving performance of manual wheelchairs are assisted propulsion systems. The hybrid manual-electric powered wheelchair propulsion system is particularly beneficial when climbing hills. In the research for an innovative wheelchair manual-electric propulsion drive system, it was found that when the wheelchair was propelled only with the hand rims, 13 pushes on the $4^{\circ}$ uphill were needed. The assisted drivetrain reduced the number of pushes required to 6-10, depending on the settings. The hybridization of the propulsion system (manual plus electric) combines, in this case, the advantages of a manual self-propelled wheelchair (physical activity, agility, good supervision over the direction and speed of movement) with the advantages of an electric wheelchair (high driving efficiency) [2]. The changes under consideration would reduce the marketing scale of electric drives, while at the same time increasing the use efficiency of natural human forces in the man-machine system. So far, the wheelchair market has been dominated by manual wheelchairs. For example, in 2004, electric wheelchairs and scooters accounted for $10.8 \%$ of all wheelchairs in use [41]. This situation is now changing. Selected advantages of electric wheelchairs translate into an increase in their share of the wheelchair market. There are emerging trends that have a direct impact on the dynamics of the wheelchair industry and include improvements in wheelchair efficiency to provide greater comfort, an increase in the use of power assist devices and the rise in popularity of hybrid wheelchair concepts [42]. Manual wheelchairs, compared with electric powered wheelchairs, are generally characterized by better durability, ease of use, suitability to maintenance, and functionality, including compatibility with various types of devices at home [43] and outdoors [44,45]. In many cases, they are also foldable for storage and transport and are customizable with various options, usually more so than power wheelchairs.

The forecasts for the demand for the wheelchair market worldwide are related to the increasing numbers of seniors and disabled people. The WHO World report on ageing and health estimates the number of people 65 years or older from 524 million in 2010 to 1500 million in 2050 [46]. Furthermore, between 0.25 and 0.50 million people worldwide yearly suffer a spinal cord injury, which remains a primary cause of demand for wheelchairs [47]. The global wheelchair market was worth USD 4730 million in 2018, and is expected to reach USD 8090 million by 2026 (CAGR $=7.0 \%$ ). Other forecasts predict that the global manual wheelchair market will grow from USD 2609.7 million to USD 4099.1 million between 2017 and 2025 (CAGR $=5.8 \%$ ) [42]. According to other data, the value of the wheelchair market is expected to increase from USD 2370 million in 2019 to USD 3890 million in 2027 (CAGR of $6.3 \%$ ) [48]. The market is dominated by the manual wheelchair segment, with a revenue share of more than $60 \%$ in 2020 [49]. The segment of power wheelchairs is expected to grow at a CAGR of more than $8 \%$ between 2021 and 2028 [49]. Powered wheelchairs should not, in our opinion, completely dominate the market. Technological advances can improve the propulsion technology of manual self-propelled wheelchairs.

\section{Conclusions}

The research and analysis presented in the article show the strengths and weaknesses of the Wheelchair Cam-thread Drive (WCD). The test results for the WCD were compared with those of a typical Push-rim Drive (WPD). The WCD is a solution completely different from the WPD, and has advantages and disadvantages. Based on field tests, bench tests and computer modelling, the following conclusions can be drawn: 
1. A wheelchair with WCD can be used both as a vehicle and as a rehabilitation device. The propulsive movement of the upper limb can be changed with respect to its direction, and different 'sets' of muscles can be used for propulsion, to a much wider extent than is the case in wheelchairs with WPD. This is confirmed by the results of EMG studies and simulations with biomechanical software. Cam-shape options in a WCD wheelchair provide for a wide array of upper limb loading options individually adapted to the user;

2. Propulsion of a wheelchair with WCD requires less effort from the user. This drive succeeds in reducing the dynamic forces occurring in the initial and final phases of the propulsion cycle. The active phase of the WCD drive cycle is long, which is advantageous;

3. The results of the research and analysis of the wheelchair prototype indicate the need for design changes that would favor smoother propulsive movements and controlled braking. Such solutions are envisaged in the target design;

4. Potential WCD disadvantages, hindering its use as a vehicle, include the rapid fatigue of the upper limbs held in the raised position (if propulsion is performed solely by pulling the cords forward, i.e., by straightening the upper limbs in the horizontal position), poor maneuverability and the necessity to use brakes, which increases both the structural complexity and weight of the wheelchair.

These results have proven that the WCD drive probably requires further development. Elements that should be thoroughly investigated include: characteristics of the return motion mechanism; upper limb trajectories and their relation to the training of selected muscle groups in the upper limbs and shoulder girdle; the shape and dimensions of camdrive elements; selection of the caster type, and the method of relieving some load of them, or places of attachment of the cord under the shoulder. The WCD requires further development and research on drive biomechanics. As the design and implementation of new mobility measures for people with disabilities is an important challenge, primarily due to the need to successively reduce health risks resulting from the use of devices that overload the human-movement system, such research is well justified.

What follows indirectly from the considerations presented herein, is the need to look for new solutions for manual wheelchair drives. Manual drives will certainly never be completely replaced with electric ones due to rehabilitation-related movement needs, among other reasons. On the other hand, due to the expected increase in the number of electrically powered wheelchairs, it is reasonable to look for such technical solutions that would make people potentially interested in purchasing this type of wheelchair featuring innovative structures that require less human biological forces for propulsion than traditional ones. The design solutions proposed in this paper follow this very path. Our further work will be a continuation of the topics discussed in this paper, and will aim to quantify the benefits that new construction solutions bring from the perspective of sustainable development principles, especially environmental and social benefits.

Author Contributions: Conceptualization, M.Z.; methodology, J.G., M.Z. and D.T.; software, J.G.; validation, M.Z., J.G. and D.T.; formal analysis, A.S.; investigation, J.G. and M.Z.; resources, D.T. and P.K.; data curation, D.T.; writing-original draft preparation, M.Z. and M.S.; writing-review and editing, M.S.; visualization, M.Z; supervision, M.Z., J.G. and M.S.; project administration, M.Z.; funding acquisition, P.K. All authors have read and agreed to the published version of the manuscript.

Funding: The study was supported by the funding for statutory R\&D activities as the research task "Design, operation and modeling of transport system elements and environmental loads" no. 0416/SBAD/0003 of the Faculty of Civil and Transport Engineering, Poznan University of Technology. Poland.

Institutional Review Board Statement: Not applicable.

Informed Consent Statement: Not applicable.

Data Availability Statement: All data, models, and code generated or used during the study appear in the submitted article. 
Conflicts of Interest: The authors declare no conflict of interest.

\section{References}

1. Kager, R.; Bertolini, L.; Te Brömmelstroet, M. Characterisation of and Reflections on the Synergy of Bicycles and Public Transport. Transp. Res. Part A Policy Pract. 2016, 85, 208-219. [CrossRef]

2. Wieczorek, B.; Warguła, Ł.; Rybarczyk, D. Impact of a Hybrid Assisted Wheelchair Propulsion System on Motion Kinematics during Climbing up a Slope. Appl. Sci. 2020, 10, 1025. [CrossRef]

3. Holla, J.F.M.; van den Akker, L.E.; Dadema, T.; de Groot, S.; Tieland, M.; Weijs, P.J.M.; Deutekom, M.; on behalf of the WHEELSstudy group. Determinants of Dietary Behaviour in Wheelchair Users with Spinal Cord Injury or Lower Limb Amputation: Perspectives of Rehabilitation Professionals and Wheelchair Users. PLoS ONE 2020, 15, e0228465. [CrossRef]

4. Warguła, Ł.; Kukla, M.; Wieczorek, B. The Impact of Wheelchairs Driving Support Systems on the Rolling Resistance Coefficient. IOP Conf. Ser. Mater. Sci. Eng. 2020, 776, 012076. [CrossRef]

5. Cooper, R.A. Wheelchair Selection and Configuration; Demos: New York, NY, USA, 1998; ISBN 978-1-888799-18-7.

6. Sydor, M. Wybór i Eksploatacja Wózka Inwalidzkiego/Selection and Using a Wheelchair; Wydawnictwo Akademii Rolniczej im Augusta Cieszkowskiego: Poznań, Poland, 2003; ISBN 83-7160-315-0.

7. Sydor, M.; Zabłocki, M. Wybrane problemy doboru i konfiguracji wózka inwalidzkiego z napędem ręcznym/Chosen problems of manual wheelchair selection and configuration. Fizjoter. Pol. 2006, 2, 172-177.

8. Cooper, R.A.; Koontz, A.M.; Ding, D.; Kelleher, A.; Rice, I.; Cooper, R. Manual Wheeled Mobility-Current and Future Developments from the Human Engineering Research Laboratories. Disabil. Rehabil. 2010, 32, 2210-2221. [CrossRef]

9. Branowski, B.; Zabłocki, M. Poszukiwanie potrzeby i koncepcji rynkowej innowacji projektowej wspomagającej mobilność seniorów i osób z niepełnosprawnościami/Searching for the need and the market concept of design innovation supporting the mobility of seniors and people with disabilities. In Projektowanie dla Seniorów i Osób Niepełnosprawnych. Badania. Analizy. Oceny. Konstrukcje; Branowski, B., Ed.; Wydział Maszyn Roboczych i Transportu Politechniki Poznańskiej: Poznań, Poland, 2015 pp. 108-122, ISBN 978-83-941828-0-9.

10. Sydor, M.; Janicki, S. Wózki dla osób niepełnosprawnych/Wheeled vehicles for people with disabilities. In Wyroby Medyczne. Zaopatrzenie Indywidualne; Geremek, K., Janicki, S., Przeździak, B., Woźniewski, M., Eds.; Wydawnictwo Lekarskie PZWL: Warsaw, Poland, 2016; pp. 179-210, ISBN 978-83-200-5151-3.

11. Chow, J.W.; Levy, C.E. Wheelchair Propulsion Biomechanics and Wheelers' Quality of Life: An Exploratory Review. Disabil. Rehabil. Assist. Technol. 2011, 6, 365-377. [CrossRef]

12. McLaurin, C.A.; Brubaker, C.E. Biomechanics and the Wheelchair. Prosthet. Orthot. Int. 1991, 15, 24-37. [CrossRef]

13. Hosseini, S.M.; Oyster, M.L.; Kirby, R.L.; Harrington, A.L.; Boninger, M.L. Manual Wheelchair Skills Capacity Predicts Quality of Life and Community Integration in Persons with Spinal Cord Injury. Arch. Phys. Med. Rehabil. 2012, 93, 2237-2243. [CrossRef]

14. Hiremath, S.V.; Intille, S.S.; Kelleher, A.; Cooper, R.A.; Ding, D. Detection of Physical Activities Using a Physical Activity Monitor System for Wheelchair Users. Med. Eng. Phys. 2015, 37, 68-76. [CrossRef]

15. Cratsenberg, K.A.; Deitrick, C.E.; Harrington, T.K.; Kopecky, N.R.; Matthews, B.D.; Ott, L.M.; Coeytaux, R.R. Effectiveness of Exercise Programs for Management of Shoulder Pain in Manual Wheelchair Users With Spinal Cord Injury. J. Neurol. Phys. Ther. 2015, 39, 197-203. [CrossRef] [PubMed]

16. Mikołajewska, E. Wheelchair-Related Falls-A Review. Int. J. Disabil. Hum. Dev. 2013, 12, 259-266. [CrossRef]

17. Sydor, M.; Krauss, A.; Krauss, H. Risk Analysis for Operating Active Wheelchairs in Non-Urban Settings. Ann. Agric. Environ. Med. 2017, 24, 532-536. [CrossRef]

18. Flemmer, C.L.; Flemmer, R.C. A Review of Manual Wheelchairs. Disabil. Rehabil. Assist. Technol. 2016, 11, 177-187. [CrossRef]

19. Jung, H.S.; Park, G.; Kim, Y.-S.; Jung, H.-S. Development and Evaluation of One-Hand Drivable Manual Wheelchair Device for Hemiplegic Patients. Appl. Ergon. 2015, 48, 11-21. [CrossRef]

20. Howarth, S.J.; Pronovost, L.M.; Polgar, J.M.; Dickerson, C.R.; Callaghan, J.P. Use of a Geared Wheelchair Wheel to Reduce Propulsive Muscular Demand during Ramp Ascent: Analysis of Muscle Activation and Kinematics. Clin. Biomech. 2010, 25, 21-28. [CrossRef] [PubMed]

21. Nishavithri, N.; Dheepa, B.; Nithya, R.; Manoharan, S. Vehicle for Physically Challenged Person Using Tumbler Gear. Eur. J. Mol. Clin. Med. 2020, 7, 2509-2513.

22. Sarraj, A.R.; Massarelli, R. Design History and Advantages of a New Lever-Propelled Wheelchair Prototype. Int. J. Adv. Robot. Syst. 2011, 8, 26. [CrossRef]

23. Bochnacki, A.; Gwiazdowski. Patent Application PL 347277 A1. Mechanizm Kroczący/Walking Mechanism. Filled 2001.04.24, published 2002.11.04, discontinued 2010.01.29 by Polish Patent Office.

24. Quaglia, G.; Bonisoli, E.; Cavallone, P. The Design of a New Manual Wheelchair for Sport. Machines 2019, 7, 31. [CrossRef]

25. Cavallone, P.; Bonisoli, E.; Quaglia, G. Handwheelchair.q: New Prototype of Manual Wheelchair for Everyday Life. In Advances in Italian Mechanism Science; Niola, V., Gasparetto, A., Eds.; Mechanisms and Machine Science; Springer International Publishing: Cham, Switzerland, 2021; Volume 91, pp. 111-119, ISBN 978-3-030-55806-2.

26. Branowski, B.; Kurczewski, P.; Torzyński, D.; Zabłocki, M. Patent Application PL 427338 A1. Napęd Ręczny Dla Pojazdów, w Szczególności Wózków Inwalidzkich Ręcznych/Manual Drive for Vehicles, in Particular for Manual Wheelchairs. Filled 2018.10.05, published 2020.04.06, granted 2021.11.29 as a patent Pat.239349 by Polish Patent Office. 
27. Gedliczka, A.; Pochopień, P. Atlas Miar Człowieka: Dane do Projektowania i Oceny Ergonomicznej: Antropometria, Biomechanika, Przestrzeń Pracy, Wymiary Bezpieczeństwa/Atlas of Human Measures: Data for Ergonomic Design and Assessment: Anthropometry, Biomechanics, Work Space, Safety Dimensions; Centralny Instytut Ochrony Pracy: Warsaw, Poland, 2001; ISBN 978-83-88703-38-6.

28. Rankin, J.W.; Richter, W.M.; Neptune, R.R. Individual Muscle Contributions to Push and Recovery Subtasks during Wheelchair Propulsion. J. Biomech. 2011, 44, 1246-1252. [CrossRef]

29. Wieczorek, B.; Kukla, M. Biomechanical Relationships Between Manual Wheelchair Steering and the Position of the Human Body's Center of Gravity. J. Biomech. Eng. 2020, 142, 081006. [CrossRef] [PubMed]

30. Wieczorek, B.; Kukla, M.; Warguła, Ł. The Symmetric Nature of the Position Distribution of the Human Body Center of Gravity during Propelling Manual Wheelchairs with Innovative Propulsion Systems. Symmetry 2021, 13, 154. [CrossRef]

31. Van der Slikke, R.; Berger, M.; Bregman, D.; Veeger, D. Push Characteristics in Wheelchair Court Sport Sprinting. Procedia Eng. 2016, 147, 730-734. [CrossRef]

32. Kukla, M.; Wieczorek, B.; Warguła, Ł.; Berdychowski, M. An Analytical Model of the Demand for Propulsion Torque during Manual Wheelchair Propelling. Disabil. Rehabil. Assist. Technol. 2021, 16, 9-16. [CrossRef] [PubMed]

33. Kloiber, M.; Drdácký, M.; Machado, J.S.; Piazza, M.; Yamaguchi, N. Prediction of Mechanical Properties by Means of SemiDestructive Methods: A Review. Constr. Build. Mater. 2015, 101, 1215-1234. [CrossRef]

34. Zabłocki, M.; Branowski, B.K.; Kurczewski, P.; Torzyński, D.; Bonenberg, A.; Gabryelski, J.; Głowala, S.; Pohl, P.; Rychlik, M.T.; Sydor, M.; et al. Wprowadzenie do Inżynierii Rehabilitacyjnej/Introduction to Rehabilitation Engineering; Zabłocki, M., Ed.; Wydział Maszyn Roboczych i Transportu Politechniki Poznańskiej: Poznań, Poland, 2017; ISBN 978-83-941828-1-6.

35. Wieczorek, B.; Kukla, M.; Rybarczyk, D.; Warguła, Ł. Evaluation of the Biomechanical Parameters of Human-Wheelchair Systems during Ramp Climbing with the Use of a Manual Wheelchair with Anti-Rollback Devices. Appl. Sci. 2020, 10, 8757. [CrossRef]

36. Boninger, M.L.; Souza, A.L.; Cooper, R.A.; Fitzgerald, S.G.; Koontz, A.M.; Fay, B.T. Propulsion Patterns and Pushrim Biomechanics in Manual Wheelchair Propulsion. Arch. Phys. Med. Rehabil. 2002, 83, 718-723. [CrossRef] [PubMed]

37. Kumar, S. (Ed.) Biomechanics in Ergonomics, 2nd ed.; CRC Press: Boca Raton, FL, USA, 2008; ISBN 978-0-8493-7908-6.

38. Salvendy, G. (Ed.) Handbook of Human Factors and Ergonomics, 4th ed.; Wiley: Hoboken, NJ, USA, 2012; ISBN 978-0-470-52838-9.

39. WHO Assistive Technology. Available online: https://www.who.int/news-room/fact-sheets/detail/assistive-technology (accessed on 24 September 2021).

40. Branowski, B.; Zabłocki, M.; Sydor, M. The Material Indices Method in the Sustainable Engineering Design Process: A Review. Sustainability 2019, 11, 5465. [CrossRef]

41. Sapey, B.; Stewart, J.; Donaldson, G. The Social Implications of Increases in Wheelchair Use: Report; Department of Applied Social Science, Lancaster University: Lancaster, UK, 2004; ISBN 978-1-86220-153-8.

42. Sable, K. Global Manual Wheelchair Market; Allied Market Research: Portland, OR, USA, 2019; p. 222.

43. Bonenberg, A.; Branowski, B.; Kurczewski, P.; Lewandowska, A.; Sydor, M.; Torzyński, D.; Zabłocki, M. Designing for Human Use: Examples of Kitchen Interiors for Persons with Disability and Elderly People. Hum. Factors Ergon. Manuf. Serv. Ind. 2019, 29, 177-186. [CrossRef]

44. Branowski, B.; Pohl, P.; Rychlik, M.; Zablocki, M. Integral Model of the Area of Reaches and Forces of a Disabled Person with Dysfunction of Lower Limbs as a Tool in Virtual Assessment of Manipulation Possibilities in Selected Work Environments. In Universal Access in Human-Computer Interaction: Users Diversity, Pt 2, Proceedings of the 6th International Conference, UAHCI 2011, Orlando, FL, USA, 9-14 July 2011; Stephanidis, C., Ed.; Springer: Berlin/Heidelberg, Germany, 2011; Volume 6766, pp. 12-21, ISBN 978-3-642-21662-6.

45. Branowski, B.; Pacholski, L.; Rychlik, M.; Zabłocki, M.; Pohl, P. Studies on a New Concept of 3D Data Integration about Reaches and Forces of a Disabled Person on a Wheelchair (CAD Methods in Car and Market Ergonomics). Hum. Factors Ergon. Manuf. Serv. Ind. 2013, 23, 255-266. [CrossRef]

46. World Health Organization. World Report on Ageing and Health; World Health Organization: Geneva, Switzerland, 2015; ISBN 92-4-156504-7.

47. Wheelchair Market; Fortune Business Insights: Pune, India, 2020; p. 145.

48. Wheelchair Market by Type (Manual and Electric), by Application (Pediatric and Adults), by End-User (Homecare, Ambulatory Surgical Centers, Hospitals, Rehabilitation Centers), 2017-2027; Consumer Goods; Marketysers Global Consulting LLP: Pune, India, 2020.

49. North America Wheelchair Market Size, Share E Trends Analysis Report by Application (Hospitals, Homecare, ASCs), by Product (Manual, Electric), by Category Type, by Country, and Segment Forecasts, 2021-2028; Grand View Research, Inc.: San Francisco, CA, USA, 2021; p. 100. 